\title{
Annular tears in the dorsolumbar spine
}

\author{
R. C. HILTON, ${ }^{1}$ J. BALL, ${ }^{2}$ AND R. T. BEN ${ }^{2}$
}

From the ${ }^{1}$ Department of Rheumatology, Hope Hospital, Manchester; the ${ }^{2}$ Department of Rheumatology, University of Manchester; and the ${ }^{2}$ Department of Community Medicine, University of Manchester

SUMMARY As part of a systematic study of the spine between D11 and S1 the distribution and severity of anterior and posterior annular tears has been assessed by charting the tears in sagittal slabs of 117 fresh specimens. No significant sex difference was seen. The number of cases with tears in multiple discs increases with age, but exceptions to this trend occurred in both young and elderly spines. Age adjusted correlation coefficients indicate that anterior and posterior tears at L4 and L5 do not predict tears at other levels. At L3 and above, significant positive correlations occur between multiple disc levels, particularly posteriorly. In patients 50 years old or more the mean anterior tear score rises sharply from L5 to peak at L2 and L1, but, in contrast, the mean posterior tear score falls from L4 to L1 in this age group. The increase in severity of anterior tears corresponds with increased mobility in the L4-L1 discs from 50-70 years. The data are compatible with 2 factors causing tears. One affects L4 and L5 in young adults and is possibly mechanical in nature; the second operates at a later age, promotes widespread disc involvement, and is primarily degenerative in nature. The increased prevalence and severity of anterior tears (and the associated increase in mobility) in the upper lumbar region in the middle aged and elderly may be a pathogenic factor in back pain for this age group.

Systematic studies of annular tears have been infrequent and usually concentrated on those occurring posteriorly in the lumbar region. Tears which occur at the dorsolumbar junction may, however, be of importance in the study of low back pain, particularly as it has been suggested that this region is susceptible to torsional stresses. ${ }^{12}$. Anterior tears have been neglected, and the purpose of the present study was to examine systematically the severity of both anterior and posterior tears together with their relationship to age. The results were obtained as part of a systematic study of the spine below D9.

\section{Material and methods}

The material consisted of 124 selected post-mortem specimens of the lower spine. Spines were not removed from patients who had received long term corticosteroids or who were known to have neoplasia or metabolic bone disease. Histological examination of an undecalcified bone block from the sacrum of each spine revealed 5 patients with osteomalacia and 2 with mild secondary hyperparathyroidism. These patients were excluded.

Accepted for publication 4 December 1979

Correspondence to Dr R. C. Hilton, Hope Hospital, Eccles Old Road, Salford M6 8HD.
There were 52 females and 65 males. The age range was 13 to 96 years. Fifty-four patients were under 50 years and 63 patients were over 50 years. Most patients had died within 1 week of admission to hospital, and none had been confined to bed for more than 1 month.

\section{ASSESSMENT OF ANNULAR TEARS}

After removing the neural arches the vertebral bodies were divided into 5 sagittal slabs. At each disc level separate scores were obtained for tears in the inner and outer annulus both anteriorly and posteriorly by first charting tears and then summating the results from each of the 5 slabs. Thus tears at the 4 sites in each slab were graded at each disc level on a scale 0 to 5 , the total score at each disc level depending on the number of slabs affected. These scores were taken to represent the severity of the tear. Tears involving the outer annulus (major), and being close to or involving the common ligament, were considered to be more severe than tears confined to the inner annulus (minor). Extensive tears involving the whole disc were occasionally present, particularly in elderly patients, but in the analysis of the results the anterior and posterior sections were treated separately.

In all cases a complete section of the D11 and L4 
discs with adjacent bone was examined histologically. All discs were graded separately for osteophytes and disc narrowing on a 0 to 3 scale.

\section{Results}

\section{DISTRIBUTION OF MEAN DISC}

TEAR SCORE

It can be seen (Fig. 1) that the severity of posterior tears (as expressed by the mean disc tear score) falls progressively from L4 to D12 in females and from L5 in males. The mean anterior tear score is much lower than the mean posterior tear score at L5 and L4 but greater at L2 and above. Thus the severity pattern of posterior disc tears is different from those of the anterior annulus and this is true for both males and females.
RELATIONSHIP OF ANNULAR TEARS TO AGE The mean total anterior and posterior tear scores increase with age as expected (Fig. 2). Below the age of 50 years the mean score for posterior tears is greater than that for anterior tears, but thereafter the position is reversed (Fig. 2).

Dividing the patients into age groups less than 50 years and 50 years and over reveals that the distribution of mean anterior and posterior tear scores behaves differently with respect to age. Considering posterior tears (Fig. 3), the mean score falls from L5 to D11 in both sexes in patients under 50 years of age; over the age of 50 years this pattern is virtually unchanged, though the mean score is greater at each disc level. The increase is greater at $\mathrm{L4}, \mathrm{L} 3$, and $\mathrm{L} 2$ than at other levels (Fig. 3). In contrast the distribution of mean anterior tear scores differs in those
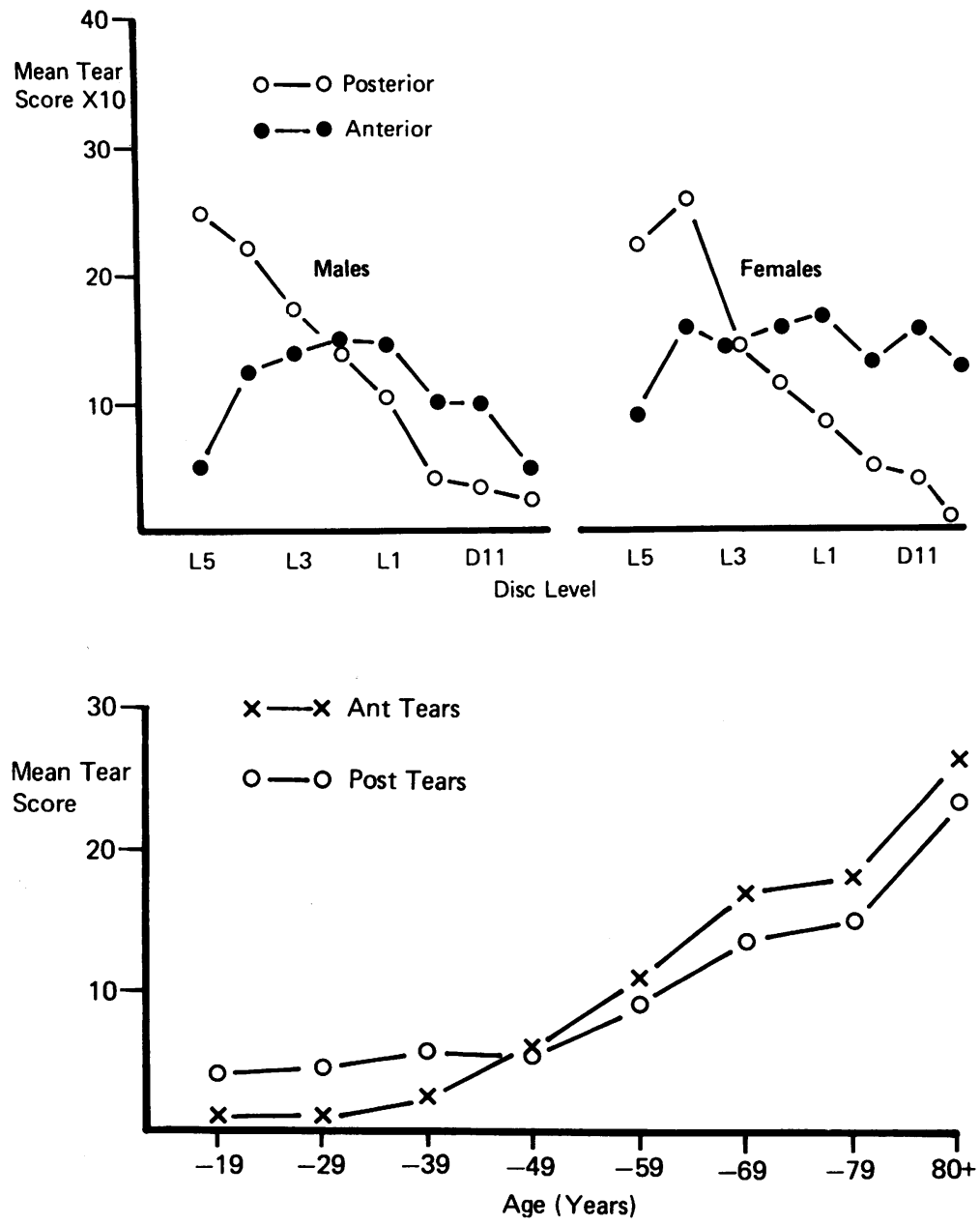

Fig. 1 Mean anterior and posterior disc tear score by disc level

Fig. 2 Mean total (D10-L5) anterior and posterior disc tear score by age 


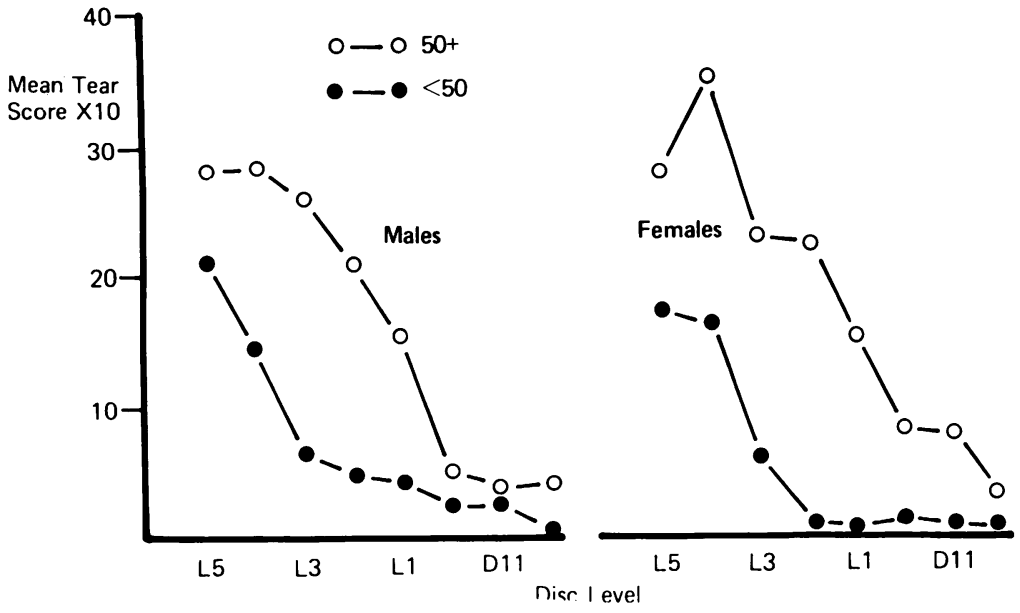

Fig. 3 Mean posterior disc tear score by age and disc level

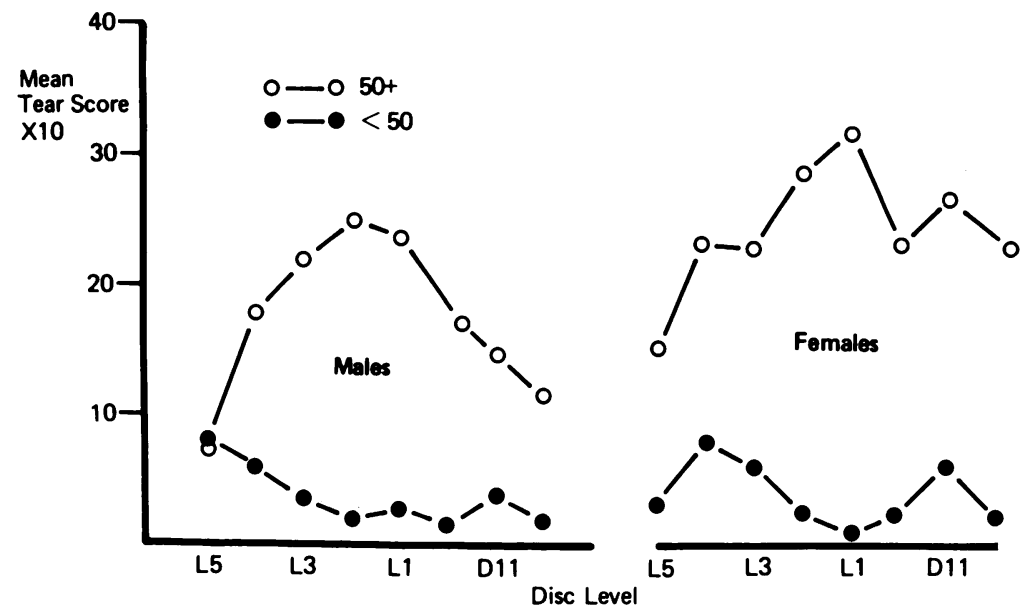

Fig. 4 Mean anterior disc tear score by age and disc level

aged less than 50 years and those aged 50 years and over. The mean anterior tear score in both sexes under 50 years of age is low; in males it falls from L5 to L2 and in females from L4 to L1 (Fig. 4). As with posterior tears the mean anterior tear score in both sexes at each disc level increases with age (with the exception of L5 in males), but the change with age differs from that found with posterior tears (Fig. 4). Although the greatest increase is at $\mathrm{L} 2$ and $\mathrm{L} 1$ the increase at $\mathrm{L} 1, \mathrm{D} 12$, and D11 is far greater than the corresponding increase in the mean posterior tear score at these levels (Fig. 4). Thus in patients 50 years and over the mean anterior tear score peaks at $\mathrm{L} 2$ and $\mathrm{L} 1$ in both sexes, whereas the mean posterior tear score shows no such peak.

The proportion of cases with tears of any grade increases in frequency with age in both the L2 to L5 and D10 to $\mathrm{L} 1$ regions (Table 1). However, in
Table 1 Distribution of cases with disc tears by age and spinal region

\begin{tabular}{lllll}
\hline Age (years) & \multicolumn{2}{l}{ Cases } & & \\
\cline { 2 - 5 } & $\begin{array}{l}\text { L2-L5 } \\
\text { No. }\end{array}$ & $\%$ & & $\begin{array}{l}\text { D10-LI } \\
\text { No. }\end{array}$ \\
& & $\%$ & $\%$ \\
\hline$<30$ & $12^{*}$ & $54 \cdot 6$ & $4^{*}$ & $18 \cdot 0$ \\
$30-49$ & 18 & $56 \cdot 3$ & 11 & $34 \cdot 4$ \\
$50-69$ & 32 & $80 \cdot 0$ & 23 & $57 \cdot 5$ \\
$70+$ & 22 & $95 \cdot 6$ & 22 & $95 \cdot 6$ \\
\hline
\end{tabular}

${ }^{*} \mathrm{P}<0.05$.

patients less than 30 years old the frequency with which the D10 to $L 1$ region is involved is significantly less than for the $\mathrm{L} 2$ to $\mathrm{L} 5$ region. Thereafter the frequency of involvement of the D10 to L1 region increases with age, eventually reaching parity with the L2 to L5 region in patients 70 years and over. 
Table 2 Distribution of cases with tears by age and number of affected discs

\begin{tabular}{lllll}
\hline $\begin{array}{l}\text { Discs with } \\
\text { tears } \text { (no.) }\end{array}$ & \multicolumn{4}{l}{ Cases (no.) } \\
\cline { 2 - 5 } & $<30 y r$ & $30-49 y r$ & $50-69 y r$ & $70+y r$ \\
\hline $0-1$ & 11 & 3 & 2 & 0 \\
$2-3$ & 7 & 9 & 8 & 0 \\
$4-5$ & 4 & 13 & 9 & 2 \\
$6-8$ & 1 & 6 & 21 & 21 \\
Total cases & 23 & 31 & 40 & 23 \\
\hline
\end{tabular}

The distribution of cases with respect to the number of discs affected with tears of any severity is shown in Table 2. As expected, the number of cases with multiple disc involvement increases with age. In the group under 30 years $85 \%$ of cases have 3 or fewer discs affected, but in the $50+$ age group $81 \%$ of cases have more than 3 discs involved. Exceptions do, however, occur, and 2 patients less than 30 years old had 5 or more discs with tears, while each of 2 patients aged $50+$ years had only 1 affected disc.

\section{RELATIONSHIP OF ANNULAR TEARS AT}

DIFFERENT DISC LEVELS

For minor anterior and posterior tears significant positive correlations were infrequent between adjacent discs.

As regards major anterior and posterior tears, significant positive correlations occur between all immediately adjacent discs between D11 and L3 but not between L3 and L4 and L4 and L5. Thus major tears at L4 and L5 do not predict tears at other levels. By contrast, however, posterior tears between $L 3$ and D10 show significant positive correlations with similar tears at many other levels, and this is also seen less strikingly with anterior tears.
Thus multiple disc susceptibility to major posterior and anterior tears seems to be more characteristic of the dorsolumbar spine than the lower lumbar spine.

\section{RELATIONSHIP OF ANNULAR TEARS TO TO OSTEOARTHROSIS}

Although moderate and severe osteoarthoisis of the facets occurs predominantly in the L5 to L2 region in the $50+$ age group, age-corrected correlation coefficients did not show any evidence of a relationship between anterior or posterior annular tear scores and osteoarthrosis at any disc level. Thus it would appear that osteoarthrosis can develop with age independently of tears or the factors causing tears.

\section{RELATIONSHIP OF ANNULAR TEARS TO OSTEOPHYTE FORMATION}

In both males and females 50 years old or more the mean scores for anterior and posterior tears at each disc level are greater in discs with osteophytes than in those without osteophytes (Fig. 5). However, osteophytes unassociated with tears are seen and 51 such discs were found in 34 cases. They were scattered fairly evenly at all disc levels except at D10, where there were $19(37 \%)$, and at L5, where there was only $1(0.5 \%)$. Annular tears frequently occur without osteophytes, but this is to be expected, as there is a time lag between the development of the tears and the development of osteophytes.

\section{RELATIONSHIP OF ANNULAR TEARS TO SAGITTAL MOBILITY}

In patients under 50 age-corrected correlation coefficients were significantly positive between mobility and anterior or posterior tears at L5 in

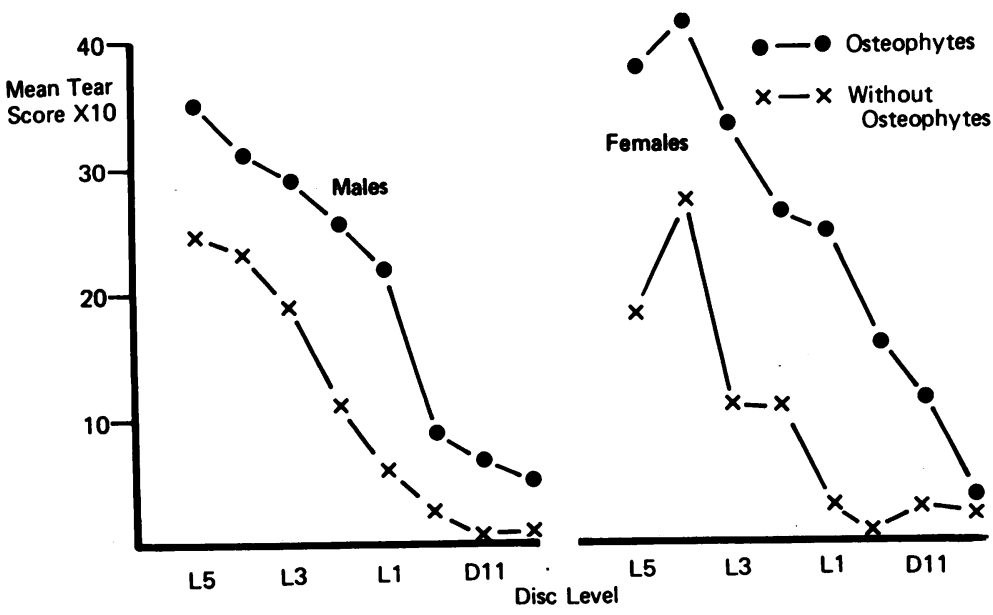

Fig. 5 Mean posterior tear score for discs with and without osteophytes by disc level in cases over 50 years 


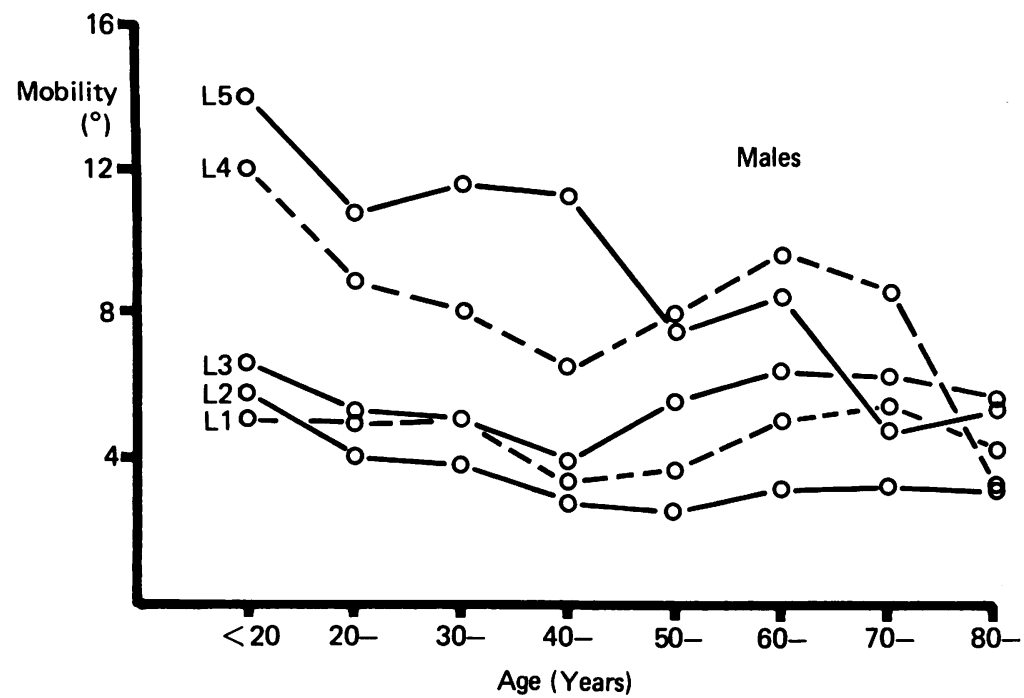

Fig. 6 Mean mobility by age and disc level
Table 3 Mean anterior and posterior tear scores at L4 and L5 in cases < 50 years: (a) all discs; (b) discs with mobility greater than 1 standard deviation above the mean

\begin{tabular}{|c|c|c|c|c|c|c|}
\hline Disc level & \multicolumn{2}{|c|}{$\begin{array}{l}\text { Mean tear score } \\
\text { Anterior }\end{array}$} & \multicolumn{2}{|c|}{ Posterior } & \multicolumn{2}{|c|}{ Discs (No.) } \\
\hline \multicolumn{7}{|l|}{ Males } \\
\hline L5 & 0.9 & $1 \cdot 9$ & $2 \cdot 4$ & $3 \cdot 6$ & 29 & 8 \\
\hline L4 & 0.7 & 0 & $1 \cdot 6$ & $2 \cdot 0$ & 29 & 2 \\
\hline \multicolumn{7}{|l|}{ Females } \\
\hline & $0 \cdot 2$ & 0.5 & $1 \cdot 7$ & $2 \cdot 3$ & 25 & 8 \\
\hline L4 & 0.8 & $2 \cdot 7$ & $1 \cdot 7$ & $4 \cdot 3$ & 25 & 3 \\
\hline
\end{tabular}

males $(P<0.05)$ and approached significance between mobility and posterior tears at $\mathrm{L} 4$ and $\mathrm{L} 5$ in females $(P<0.057)$ and $P<0.058)$. A significant positive correlation was also found between mobility and posterior tears at $\mathrm{L} 3$ in females $(\mathrm{P}<0.05)$.

In both males and females under 50 years discs with mobility above 1 standard deviation from the mean had anterior and posterior tear scores above the mean at L4 and L5 with the exception of anterior tears at $\mathrm{L} 4$ in males (Table 3).

In the $50+$ age group the marked increase in severity of anterior and posterior tears between L4 and $L 1$ corresponds in both sexes with increased mobility in the same discs (Fig. 6). The weak correlation coefficients between mobility and tears in this region in the over-50 age group could be explained by the fact that the mobility first rises and then falls.

\section{Discussion}

A criticism frequently levelled against the study of annular tears is that it is difficult to distinguish pathological tears from those that are artefactual. As part of our systematic study we have examined histologically the central slab from all the D11 and L4 discs, and it is apparent that most of the tears are associated with vascular invasion, disc degeneration, or a vertebral rim lesion. Thus, while we accept that a few of the tears we have recorded may be due to the investigative procedure, this is unlikely to apply to the large majority.

Most attention has in the past been directed to studying the distribution of tears in the L4 and L5 discs. Our findings confirm previous observations that posterior tears are most frequent in the lower two lumbar discs ${ }^{34}$ and that they first appear at this site during the second decade. ${ }^{5}$

In contrast previous investigators have given very little attention to the distribution of tears in the upper lumbar region and around the dorsolumbar junction. Farfan et al. ${ }^{4}$ implied that tears in this region were unimportant, and Friberg and $\mathrm{Hirsch}^{3}$ merely stated that tears could occur anteriorly.

In our material, as expected, the number of discs with tears increases with age, but discs in the L2-L5 region tended to be affected before those in the D10L1 region.

Our findings suggest that the patterns of severity (the distribution of mean tear score by disc level) for anterior and posterior tears are similar in patients under 50 years but differ in patients aged 
50 years and over. The mean posterior tear score for individual discs falls from L4 in patients under 50 , and this pattern is maintained in those aged 50 or over, though the score is greater at each disc level. By contrast the pattern for anterior tears changes markedly with age. Thus, while patients under 50 show a fall in the mean anterior tear score from L4 to $\mathrm{L} 1$, in those aged 50 or over the mean anterior tear score rises from L5 to peak at L2 and L1 in both sexes. Thus the mean anterior tear scores at $\mathbf{L l}$ and above are considerably higher than those for posterior tears in the patients aged 50 or over.

We have found (unreported data) that vascular invasion is far more frequent in the anterior annulus at L4 than at D11. Since it is reasonable to assume that vascularisation occurs in nonstressed areas, this finding implies that there is greater stress on the anterior disc in the upper lumbar and dorsolumbar region, and this in turn accords with the prominence of anterior tears in these regions recorded in the present study.

A study of age-corrected correlation coefficients indicates that anterior and posterior tears at L5 and L4 do not predict tears at other levels. This contradicts the suggestion of Jayson et al. ${ }^{6}$ that disc degeneration if present is found at all levels and hence may be a systemic disease.

We have found at L3 and above that both severe anterior and posterior tears tend to occur in adjacent discs. In addition significant positive correlations between multiple disc levels were seen only in the region L3 to D10 particularly posteriorly. This would suggest that 2 different factors may cause tears.

One factor affecting L4 and/or L5 in young adults is unassociated with tears at other levels and is therefore possibly mechanical in nature. Another factor affecting the dorsolumbar region promotes multiple disc involvement, becomes evident in the middle aged and elderly, and is possibly degenerative in nature.
Before the age of 50 mobility falls at all disc levels, and it is therefore unlikely that the subsequent rise at $\mathrm{L} 4, \mathrm{~L} 3, \mathrm{~L} 2$, and $\mathrm{L} 1$ is due to the continued isolated loss of mobility at L5. We have already argued (see above) that tears are degenerate at L3 and above, and it may be that these degenerate tears predispose to the increased mobility of the dorsolumbar spine, and that this is followed by secondary adaptive loss of mobility at L5. This suggestion is supported by the absence of a local explanation for the continuing fall in mobility at L5 such as disc narrowing or osteophytes. ${ }^{7}$ The increased prevalence and severity of anterior tears (and the associated increase in mobility) in the upper lumbar region in the middle aged and elderly may be a pathogenic factor in back pain for this age group.

\section{References}

1 Farfan H F, Cossette J W, Robertson G H, Wells R V, Kraus $H$. The effects of torsion on the lumbar intervertebral joints: the role of torsion in the production of disc degeneration. J Bone Joint Surg 1970; 52A: 468-97.

2 Markolf K, Morris J M. The structural components of the intervertebral disc. A study of their contributions to the ability of the disc to withstand compressive forces. $J$ Bone Joint Surg 1974; 56A: 675-87.

${ }^{3}$ Friberg S, Hirsch C. Anatomical and clinical studies on lumbar disc degeneration. Acta Orthop Scand 1950; 19: 222-42.

4 Farfan H F, Huberdeau R M, Dubow H I. Lumbar intervertebral disc degeneration. The influence of geometrical features on the pattern of disc degenerationA post mortem study. J Bone Joint Surg 1972; 54A: 492-510.

5 Hirsch C, Schajowicz F. Studies on structural changes in the lumbar annulus fibrosus. Acta Orthop Scand 1953; 22: 184-231.

6 Jayson M I V, Herbert C M, Barks J S. Intervertebral discs: nuclear morphology and bursting pressures. Ann Rheum Dis 1973; 32: 308-15.

7 Hilton E C, Ball J, Benn R T. In-vitro mobility of the lumbar spine. Ann Rheum Dis 1979; 38: 378-83. 